\title{
Relation between Fine Ferrite-Pearlite Microstructure Produced by Con- trolled Rolling and Cooling and the Subsequent Rapid Spheroidization of Medium Carbon Steel
}

Yutaka Kanetsuki, Masaaki Katsumata and Tsuyoshi Inoue

\begin{abstract}
Synopsis :
In the process of making structural parts, spheroidization treatment of the rolled bars is applied to obtain good cold forgeability. In this study, the effect of using controlled rolling and cooling process on the subsequent spheroidization behavior of medium carbon steel was investigated using a hot deformation simulater and transmission electron microscope.
\end{abstract}

The following results were obtained.

(1) By controlling the cooling rate to $10^{\circ} \mathrm{C} / \mathrm{s}$ immediately after controlled rolling, the post dynamically recrystallized fine austenite grains did not grow and transformed to a fine and globular ferrite-pearlite microstructure. This microstructure revealed an extremely high volume fraction of ferrite compared with a microstructure transformed from coarse austenite grains.

(2) By using transmission electron microscope, fine ferrite-pearlite microstructure transformed from fine dynamic-recrystallized austenite grain was observed. It was found that the extrinsic grain boundary dislocations were inherited from residual strain due to rapid cooling during the post dynamic recrystallization state. Furthermore, cementite films, which suggest an enhanced diffusion of carbon along the nonequilibrium boundary structure, were formed along each phase boundary.

The discussion is also made about the enhanced spheroidization during intercritical annealing on the basis of the behavior of grain boundary dislocations during reheating.

Key words : medium carbon steel ; dynamic recrystallization; spheroidization; grain boundary dislocation ; ferrite-pearlite ; controlled rolling ; controlled cooling.

\section{1. 緒言}

現在, 制御圧延, 制御冷却などの加工熱処理的手法が 鉄鋼材料の製造プロセスに適用されてきている1).しか し，線材，棒鋼の分野では鋼板の分野に比べ適用されて いる例は少ない。その理由の-.つとして, 仕上压延段階 で著しい加工速度の上昇のため急激な温度上昇を伴うた めである.しかし，最近は圧延中の冷却法の改善により 線材，棒鋼への制御压延の適用が可能な状況になりつつ ある ${ }^{2)}$.また他の理由として，条鋼製品の多くは中，高 炭素鋼が用いられており, 各種の複雑な機械構造用部品
に加エするためには軟質化焼鈍の必要があり,制御压延, 制御冷却だけでは加广性を付与することに十分対応でき ないためである。しかしながら，従来の軟質化焼鈍は長 時間, 高温の熱処理を要するため, その軟質化促進の… 環として制御圧延, 制御冷却による前組織の調整が検討 されてきている.

著者らは制御圧延，制御冷却技術を中炭素鍕に適用す ることにより球状化焼鈍時間を短縮化することが叮能で あることを既に報告している3). その中で, 制御压延, 制御冷却によってフェライト・パーライト組織の微細化 が叮能であること，また，フェライト粒の形状がこれら

平成元年 3 月 17 日受付 (Received Mar. 17, 1989)

* (株)神戸製鋼沂鉄鋼技術研究所 (Iron \& Steel Research Laboratories, Kobe Steel, Ltd., 1-3-18 Wakinohama-cho Chuo-ku Kobe 651)

*2（株）神戸製鋼所鉄鋼技術研究所 I. 博（Iron \& Steel Research Laboratories, Kobe Steel, Ltd.) 
の条件によって大きく変化すること，挹よび初析フェラ イトの体積率が大きく变化することと, これらの組織変 化によってその後の二相域温度に拀け球状化处理過程 での組織変化の観察結果との関係については考察した。

しかし，このような組織変化とオーステナイトの動的再 結昆との関係についてはまだ不明である。フェライト変 態に及ぼす加亡オーステナイト粒の効果については，低 苂素鎆での研究は数多くあるが4)5), 中炭素鋼に関して。 特に球状化挙動との関連での報告は少ない。

したがって，本研究では压延制御による，とくに熱間 加上後の冷却速度と動的再結昆粒の成辰及びその後の フェライト・パーライト変態,さらにその球状化促進効 果について検㗅することを目的とした。

\section{2. 実 験 方 法}

Table 1 は用いた中炭素鋼の化学成分を示している. 熱間加にには富土電波さ業製の加にフォーマス夕ーを用 いた。試験片は $34 \mathrm{~mm} \phi$ の熱間压延棒鋼を $25 \mathrm{~mm} \phi に$ 熱間鉔造し,つづいて $8 \mathrm{~mm} \phi \times 12 \mathrm{mml}$ の问简状に機 械加しした．Fig. 1 は用いた加1，ヒートパターンを示 している，超微細フェライト・パーライト組織を得るた

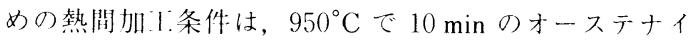

Table 1. Chemical composition of steel used (wt \%).

\begin{tabular}{ccccccc}
\hline Steel & $\mathrm{C}$ & $\mathrm{Si}$ & $\mathrm{Mn}$ & $\mathrm{P}$ & $\mathrm{S}$ & $\mathrm{Cr}$ \\
\hline & $\frac{\mathrm{M}}{0.45}$ & 0.21 & 0.71 & 0.020 & 0.013 & 0.12 \\
\hline
\end{tabular}

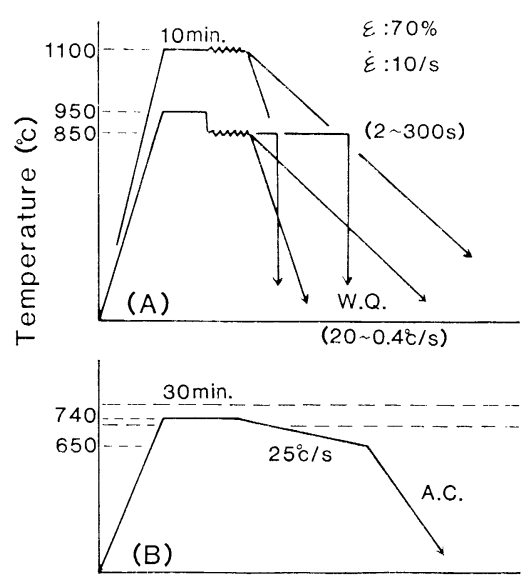

Time

(A) Thermomechanical treatment

(B) Spheroidization heat treatment

Fig. 1. Schematic illustration of experimental procedures.

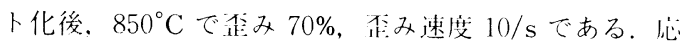
力一歪み曲線および水冷後のオ一ステナイト粒の観祭結 果より動的再結晶により超微紐才ーステナイト粆 (ASTM No. $\fallingdotseq 12)$ が得られる条作であり，詳紐は抯 報6)に示している。また，比較材としての通常历延で得 られる粗大フェライト・パーライト組織を得るために

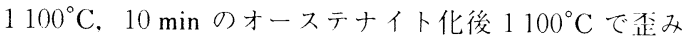

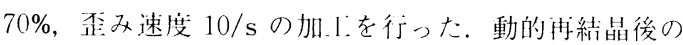
オーステナイト粒の成长過程を観祭するために, 加上後， 加上温度と同一温度で 2 - 300 s 保持した後, 水冷しオ一 ステナイト粒度を測䇥した。熱閒加儿後の連続冷却は $20 \sim 0.4^{\circ} \mathrm{C} / \mathrm{s} の$ 範网で行った。組織観祭は压維した試騃

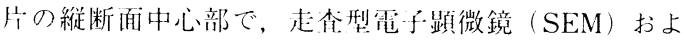
び透過電子顕微鏡（TEM）を用いて行った。

球状化処理は Fig. 1 に示す簢略型のヒートパターン で行った．球状化処理には種々のう法があるが本尖験で 用いた球状化処理は…相域に再加熱し一部再オーステナ イト化後徐冷し炭化物を球状化する力法を用いた。既に

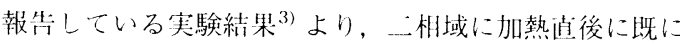
セメンタイトの分断等の組織変化が超微細フェライト・ パーライト鋼に顕著に認められたことから，本尖験では

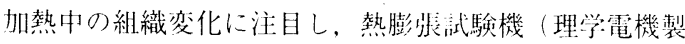
サーモフレックス TAS 100) を用いて等温から $800^{\circ} \mathrm{C}$ までの熱膨張の変化を測定した，熱膨悵測走用の試験片 は加「フォーマスターにより $3 \mathrm{~mm} t$ にル:縮した試験片 より $3 \mathrm{~mm} \phi \times 10 \mathrm{~mm} l$ の川简状試験片を採取した。し たがって，測定方问は庄縮軸に消角である。加熱速度は $5^{\circ} \mathrm{C} / \mathrm{min}$ で熱膨镸曲線を求めた。途中の $600^{\circ} \mathrm{C} よ り$ 空 冷した試験片の TEM 観祭により加熱途中の組織変化を 検歊した。

\section{3. 実 験 結 果}

\section{$3 \cdot 1$ 動的再結晶後の連続冷却速度と組織の関係}

Photo. 1 は動的再結思後, 㨁ちに0.4 2 $20^{\circ} \mathrm{C} / \mathrm{s}$ の冷 却速度で軏続的に泠却した場令の变態後のフェライト・ パーライト組織を示している. $850^{\circ} \mathrm{C}$ 熱閌加工材では フェライト・パーライト組織は冷却速度が速くなるにつ れて微綀となる傾问が認められ， $10^{\circ} \mathrm{C} / \mathrm{s}$ で最も微練で あり JIS G0551にしめされている徐泠法に準じて测起 した Gf No.で 11 番相当である。この粒度は動的再結 昆赎後直ちに水冷した場合に得られたGh No. (焼入法)

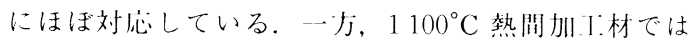
Photo. 1A，B に見られるようにフェライト・パーライ 卜組織の微細化效果はほとんど怨められない。したがっ

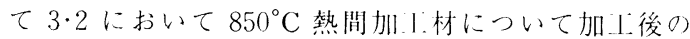




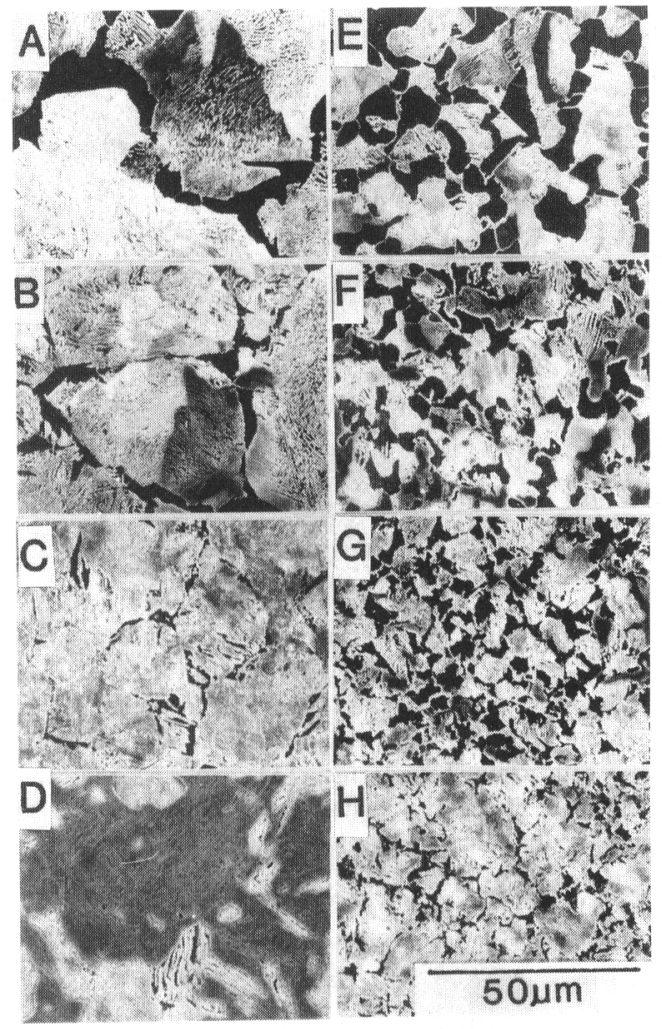

A-D : Deformed at $1100^{\circ} \mathrm{C}$

$\mathrm{E}-\mathrm{H}$ : Deformed at $850^{\circ} \mathrm{C}$

$\mathrm{A}, \mathrm{E}: 0.4^{\circ} \mathrm{C} / \mathrm{s} \quad \mathrm{B}, \mathrm{F}: 3.3^{\circ} \mathrm{C} / \mathrm{s}$

$\mathrm{C}, \mathrm{G}: 10^{\circ} \mathrm{C} / \mathrm{s} \quad \mathrm{D}, \mathrm{H}: 20^{\circ} \mathrm{C} / \mathrm{s}$

Photo. 1. SEM micrographs showing the effect of hot deformation and cooling rate on the ferrite-pearlite microstructure.

オーステナイト粒径の変化について検討した．

\section{$3 \cdot 2$ 動的再結晶後のオーステナイト粒径の変化}

Fig. 2 は $850^{\circ} \mathrm{C}$ で熱間変形後, さらに同一温度で保 持した時のオーステナイト粒度と保持時間の関係を示し

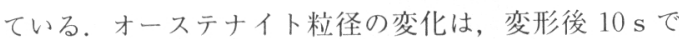
粒成長が著しく，その後の粒成長は小さい，したがって， 熱間変形後，直ちに連続冷却した場合の粒度は，その冷 却速度に応じて変態直前のオーステナイト粒径が変化し ていることを示している.さらに冷却速度が速い $10^{\circ} \mathrm{C} / \mathrm{s}$ 以上の場合には動的再結晶後のオーステナイト 粒度はほとんど変化していないことから粒内の残留歪み は一部残存し変態に関与していると考えられる。した がって, $1100^{\circ} \mathrm{C}$ 熱間加工材に比べ $850^{\circ} \mathrm{C}$ 熱間加工材で フェライト・パーライト組織の粗さの変化が大きいのは 変態直前までのオーステナイトの粒成長が $1100^{\circ} \mathrm{C}$ 熱

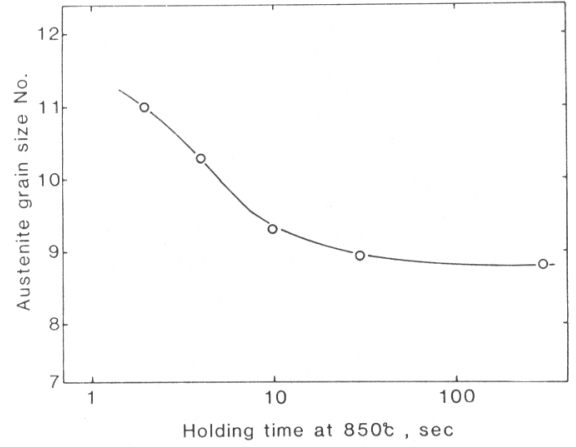

Fig. 2. Post dynamic austenite grain growth at $850^{\circ} \mathrm{C}$.

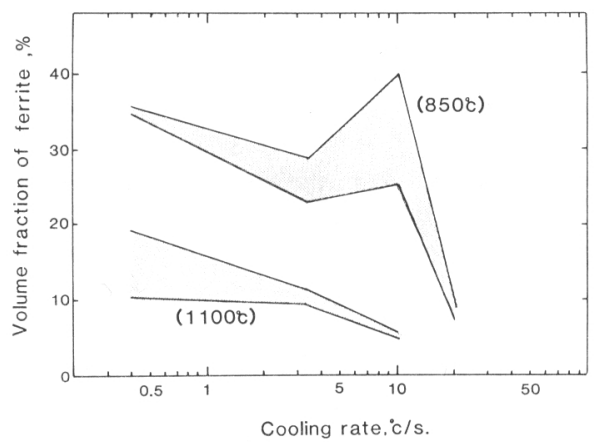

Fig. 3. Effect of hot deformation temperature and cooling rate on the ferrite volume fraction of transformed ferrite-pearlite microstructure. The deformation temperatures are indicated in parentheses.

間加工材に比べ大きく変態直前まで粒成長していること によるものと考えられる。

\section{$3 \cdot 3$ 初析フェライトの体積率と制御圧延・制御冷却条 件との関係}

次に初析フェライトの体積率と, 熱間加工条件および 冷却速度との関係を検討した結果を Fig. 3 に示す。ま ず，比較材の粗粒オーステナイトよりの変態の場合，冷 却速度が遅くなるにつれてフェライト体積率は単調に増 加する傾向を示すが，微細オーステナイトから変態した 場合体積率は粗粒オーステナイトの場合に比べいずれの 冷却速度に扔いても増加を示す。これはフェライト粒の 形状が粗粒の場合，オーステナイト粒界に沿ってフィル ム状に生成する傾向が強く粒内方向への成長が制限され ているのに対して微細粒では粒内への成長速度が大きく 塊状に析出するためと考えられる。また微細粒化により 析出サイトが増加したことも大きく寄与している．さら 


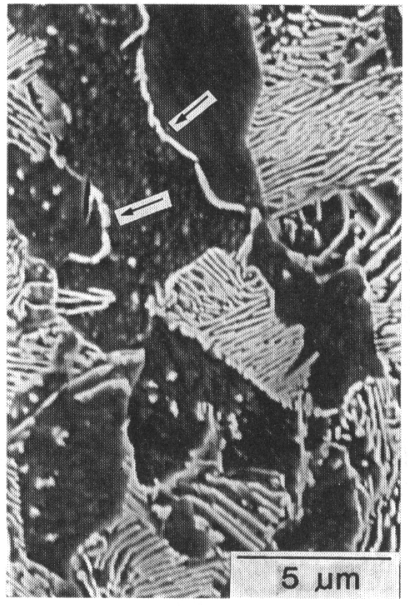

Photo. 2. SEM micrograph of the fine ferrite-pearlite microstructure showing cementite films at ferrite-ferrite boundary and small cementite precipitation in the ferrite grains. Arrows indicate cementite film at ferrite-ferrite grain boundaries.

に, $10^{\circ} \mathrm{C} / \mathrm{s}$ で泠却した場合には急激なフェライトの体 積率の増加が認められほほ標準組織（徐冷によって得ら れる平衡状態の組織）に近い体積率のフェライトの析出 が認められた。したがって, $10^{\circ} \mathrm{C} / \mathrm{s} の$ 冷却速度の場合, パーライト中の炭素濃度は共析組成に近く,このことは 炭素の搪散が促進されていることを示していると考えら れる。一方 $1100^{\circ} \mathrm{C}$ の場合体積率は $850^{\circ} \mathrm{C}$ の場合の $1 / 4$ でありパーライト中の炭素濃度は杫めて小さい。

Photo. 2 は $850^{\circ} \mathrm{C}$ で熱間加工後 $10^{\circ} \mathrm{C} / \mathrm{s}$ で泠却した場合 について SEMによって拡大して観察した結果を示して いるが，特徴としてフェライト・フェライト界面でのセ メンタイトと考えられる析出物, および粒内での孤立し たセメンタイトが認められた。これらについて,さらに TEMによって観察を行った。

\section{$3 \cdot 4$ 超微細フェライト・パーライト組織の TEM 観察結} 果

Photo. 3 は $10^{\circ} \mathrm{C} / \mathrm{s}$ で冷却して得られる超微細フェラ イト・パーライト組織の TEM 観察結果を $0.4^{\circ} \mathrm{C} / \mathrm{s}$ で泠 却した場合と比較して示している。 $10^{\circ} \mathrm{C} / \mathrm{s}$ で冷却した 場合に次に示すような特徵が認められた。（1）フェライ ト・パーライト界面拈よびフェライト・フェライト界面が 階段状である。（2)界面拉よび粒内に拈いても析出物が 認められた。これらの析出物はPhoto. 2 でも認められ た析出物に対応しており Photo. 3 に示すようにパーラ

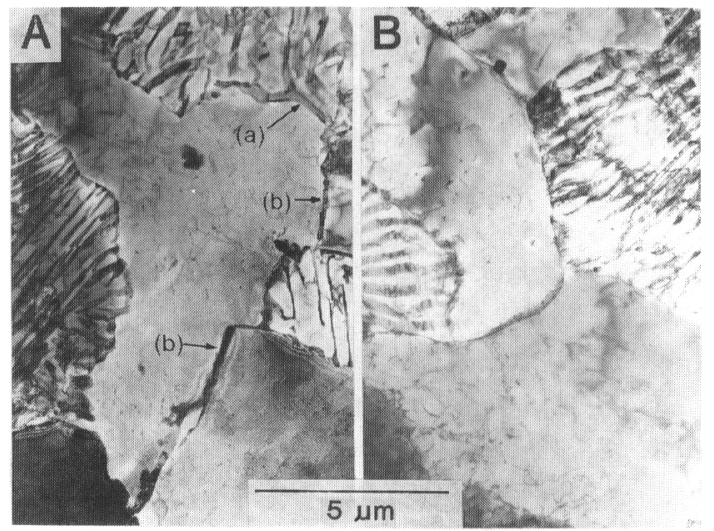

A : $10^{\circ} \mathrm{C} / \mathrm{s} \quad$ B : $0.4^{\circ} \mathrm{C} / \mathrm{s}$

Photo. 3. TEM micrographs of ferrite-pearlite microstructure transformed at cooling rate of $10^{\circ} \mathrm{C} / \mathrm{s}$ and $0.4^{\circ} \mathrm{C} / \mathrm{s}$ after hot deformation at $850^{\circ} \mathrm{C}$. By rapid cooling $\left(10^{\circ} \mathrm{C} / \mathrm{s}\right)$, shape of grain boundary became irregular and cementite films were formed at each grain boundaries. (a) and (b) indicate cementite films at ferrite-pearlite grain boundary and ferrite-ferrite grain boundary respectively.

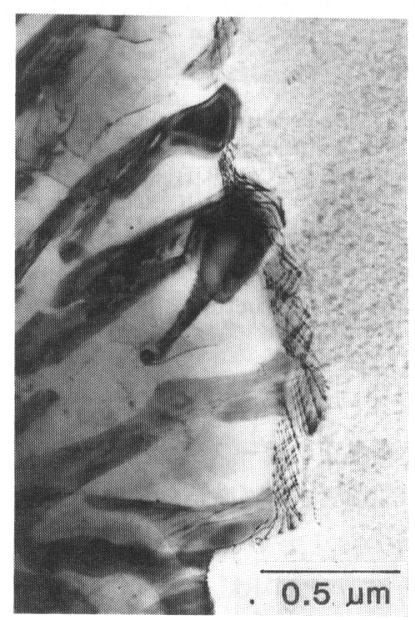

Photo. 4. TEM micrograph showing grain boundary dislocations at ferrite-pearlite boundary and ferrite-cementite boundaries of pearlite.

イト相のセメンタイトと連続していることからセメンタ イトと考えられる。したがって以下フィルム状セメンタ イトと呼ぶ.

Photo. 4 はフェライト・パーライト界面をさらに高倍 率で観察した結果を示している。粒界には多数の転位が 認められる. またPhoto. 5 はフェライト・フェライト界 


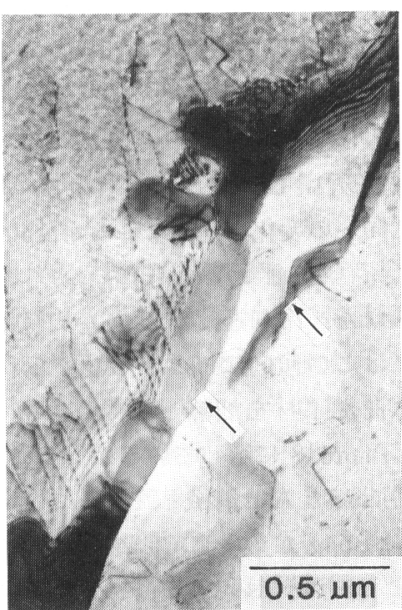

Photo. 5. TEM micrograph showing cementite film at ferrite-ferrite grain boundary. Arrows indicate cementite film at ferrite-ferrite grain boundaries.

面のフィルム状のセメンタイトを示している．また一部 粒内へのパーライト的なセメンタイトの成長も認められ る。フェライト界面とセメンタイトの位置は一部は近接 しているが必ずしも粒界上には存在しない場合がある. このことはフィルム状のセメンタイトの析出が界面に 沿ってのみ起きるものではなくオーステナイトからフェ ライトへの変態の過程と同時に進行しているものと考え られる。

$3 \cdot 5$ 超微細フェライト・パーライト組織の球状化挙動

本実験で用いた球状化処理方法は材料を二相域に加熱 し，この過程でパーライト中のセメンタイトの一部が分 解しオーステナイト相を形成し，その後残存した微細球 状セメンタイトを核にして徐冷することによりすすお ち，パーライトの再生を防止しながら球状化する方法で ある。この過程の詳細については粗粒の場合と比較して 既に報告しているが3)，超微細粒フェライト・パーライ 卜組織材に拈いては Photo. 6C に示すように極めて良 好な球状化組織が短時間で得られる。これは粗粒の場合 に比べ再生パーライトが生成しにくいことによるもの で，詳細は既報3)で述べているためここでは微細粒組織 の場合について検討した結果を述べる。

Photo. $6 \mathrm{~B}$ は $740^{\circ} \mathrm{C}$ に加熱直後急冷した場合 $\left(50^{\circ} \mathrm{C} / \mathrm{min}\right)$ の組織変化を示しているが, この段階で既 にフェライト・パーライト界面は Photo. $6 \mathrm{~A}$ の界面に比 べ不明瞭になり，パーライト中のセメンタイトは分断さ れた状態になっている. さらに Photo. 7 は $740^{\circ} \mathrm{C}$ に加

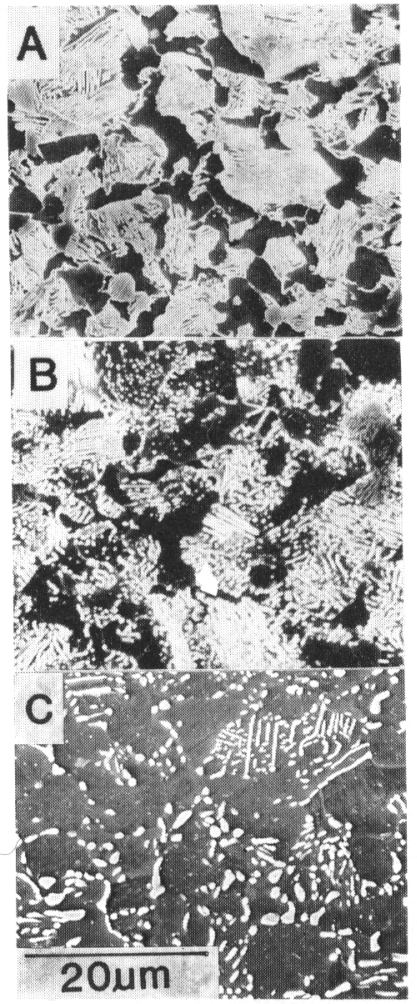

A : As transformed

B : Heated up to $740^{\circ} \mathrm{C}$ and cooled without holding time

$\mathrm{C}$ : Heated up to $740^{\circ} \mathrm{C}$ and held for $30 \mathrm{~min}$

Photo. 6. SEM micrographs showing the sequence of spheroidization behavior of fine ferrite-pearlite microstructure.
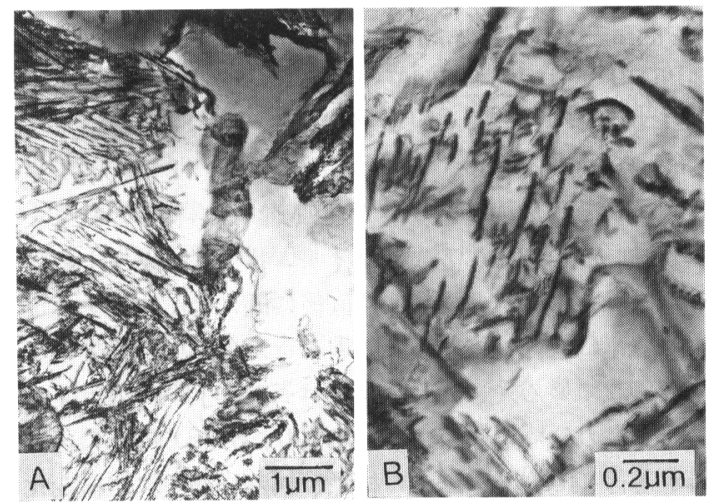

A : Dissolution of cementite film at grain boundary

B : Dissolution of pearlitic cementite in pearlite colony

Photo. 7. TEM micrographs showing early stage of spheroidization process of fine ferrite-pearlite microstructure. Specimen was water-quenched without holding time at $740^{\circ} \mathrm{C}$. 


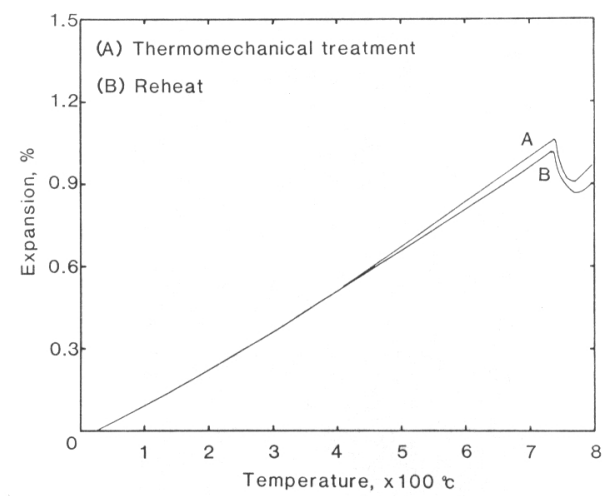

Fig. 4. Thermal expansion curves of the fine ferrite-pearlite steel produced by thermomechanical treatment.

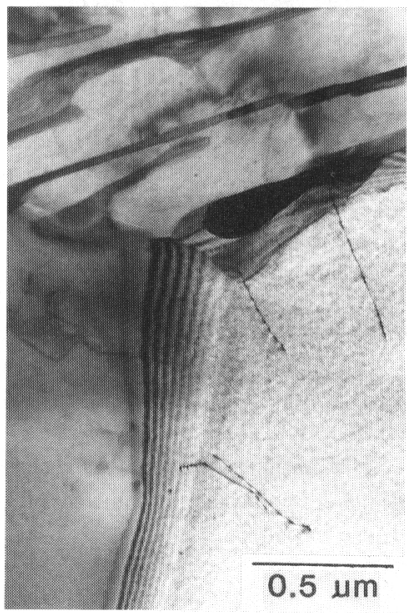

Photo. 8. TEM micrograph of ferrite-ferrite and ferrite-pearlite boundaries which was reheated up to $600^{\circ} \mathrm{C}$.

熱直後水冷した試料について TEM 観察を行った結果を 示している. Photo. 7 A はフィルム状セメンタイトの分 解の様子を示すもので，加熱直後に既にオーステナイト 化が急速に進行しており，このことが各界面の境界を不 明瞭にしている. Photo. 7 B はパーライト粒内のセメン タイト層の分解の様子を示して抢り, 分断と同時に再固 溶が進行している. 以上の結果は加熱昇温中に組織変化 が一部起こり球状化を促進している。この点が粗粒の場 合のオーステナイト化の場所がパーライトコロニー境界 である場合と大きく異なる点である ${ }^{3)}$.

そこで，加熱中の状態変化を検討する目的で，熱膨張 曲線を測定した結果をFig. 4 に，また組織変化を検討
するため TEM 観察した結果を Photo. 8 に示す. Fig. 4 では比較材として変形を加えない再加熱徐冷材を用い た。比較材はほとんど直線的な変化を示し, 約 $400^{\circ} \mathrm{C}$ における熱膨張係数は $1.31 \times 10^{-5} /{ }^{\circ} \mathrm{C}$ である。 それに 対し，熱間加工後 $10^{\circ} \mathrm{C} / \mathrm{s}$ で冷却した場合，約 $400^{\circ} \mathrm{C}$ ま では比較材と同一の変化を示しているが， $400^{\circ} \mathrm{C}$ 以上で 徐々に偏移し, 温度の上昇とともにその差は大きくなる 傾向が認められた。冷却速度が $10^{\circ} \mathrm{C} / \mathrm{s}$ よりも遅い場合 $\left(0.4^{\circ} \mathrm{C} / \mathrm{s}\right)$ にはこの傾向はほとんど認められなかった. $600^{\circ} \mathrm{C}$ まで熱間加工材を加熱した後，急冷した場合の TEM 写真を Photo. 8 に示しているが, 变態後存在して いた粒界転位はほとんど消滅していることが認められ た.したがって Fig. 4 の $400^{\circ} \mathrm{C}$ 以上での熱膨張係数の 差はVARIN ら ${ }^{7)}$ が示しているように，圧縮変形により導 入された粒界転位が昇温とともに粒界三重点へ移動消滅 し歪みを解放したことによると考えられる。

\section{4. 考察}

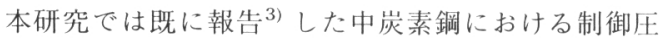
延, 制御冷却の球状化促進効果について, 制御圧延, 制 御冷却によって得られる超微細フェライト・パーライト 組織の下部組織とさらに球状化処理の加熱中に起こる変 化に注目して検討を行った，その結果，変態後の組織に ついて次のような特徴が認められた。すなわち，(1)動 的再結晶後, $10^{\circ} \mathrm{C} / \mathrm{s}$ で急冷した場合に超微細オーステ ナイト粒はその状態のままフェライト・パーライト変態 し, 変態後のフェライトの体積率は著しく増加すること が認められた。（2)TEM 観察の結果，フェライト・パー ライト界面执よびフェライト・フェライト界面には粒界 転位とフィルム状セメンタイトが形成されることが認め られた。

初析フェライトの形状, 母相との結晶学的関係につい ては低炭素鋼で多くの研究がある ${ }^{4) 577)}$ 。また制御圧延の 初析フェライトの析出に対する効果についても例えば飴 山らの研究がある4)、飴山らは初析フェライトの形状に 注目し, フィルム状㧍よび塊状の形態変化に及ぼすオー ステナイト粒度の影響を詳細な方位解析によって検討し た結果，粒界で生成するフェライトのオーステナイトに 対するバリアントの選択性によることを見出し，その原 因としてオーステナイトの粒界の平滑さに関係している としている。また, 例えば KASPER ら ${ }^{5)}$ は制御圧延によっ てフェライト変態が促進され，フェライトの体積率が増 加することを報告している。飴山らの結果は粒界の構造 が変態に影響を及ほしていることを示唆しており KASPER らの結果はオーステナイトの残留歪みが形状, 
体積摔に大きく影響していることを示唆している。本実 娩結果に扔いても初析フェライトの形状，体積率のいず 机につて变形温度，泠却条件で著しく变化する傾问が 浔められた。とくに本尖験で用いた中菼素鋼では $10^{\circ} \mathrm{C} / \mathrm{s}$ で著しいフェライトの体積摔の增加が㥨められ

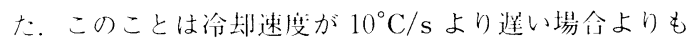
パーライト相への荻少の总激な濃維を意味しており，岸

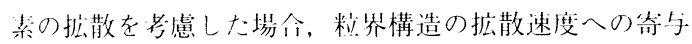
は著しく大きいものと考えられる。また，初析フェライ ト相の形状について例えば SMITH ${ }^{8)}$ は粒界で生成する第 2相の形状はそ狄ぞれの界而の土ネルギーに関係してい ることを示して抢り、粒界構造は大きな役㓶を果なして いる。 また，球状化処理のための車加熱中に粒界転位は 消滅し粒界でのセメンタイトの分解が促進されることが わかった。舟結萌時の粘界の挙動について VARIN ${ }^{9)}$ はス テンレス鋼を用い舟結昆中の䊑照について直接観察を行 い，転位が粒界に合体し粒界転位を形成した非平衡の粒 界を観祭している。また，電顕内で加熱し粒界転位の消 滅過程を検討した結果，粒界転位の消隇は鉄系の材料で 0.36〜0.42 Tm で起こることを報告している ${ }^{10)}$.この 温度は約 $400^{\circ} \mathrm{C}$ であり，Fig. 4 で得られた結果とほぼ 対忠している。したがって，本研究で梁められた粒界転 位は動的舟結晶过後に残仔した歪みが粘界転位として変 態後も継我されたもので拈加熱によって歪みの解放が引 き継いて起こったと考えられる．Fig. 5 は以上の結果に ついて，フェライトの形状㧍よび炭素の急速な拡散を考 慮した場今の変態の過程を模式的に示したもので, Photo. 3 の組織は次のような過程で形成されたものと して理解される。すなわち，初析フェライトの生成によ り排除された炭素原子が歪みの残你する非平衡の粒界に 沿って拡散した後にフィルム状セメンタイトを残してい

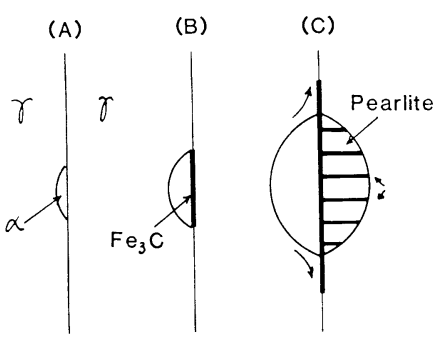

(A) Nucleation of ferrite

(B) Precipitation of cementite film

(C) Nucleation of pearlite

Fig. 5. Schematic illustration of the sequence of ferrite-pearlite transformation. Arrows indicate the diffusion of carbon atoms.
くものと考えられる。この場命，才ーステナイト界面の エネルギーは宫く，そのために生成するフェライトは塊 状を星すると考えられる。また，パーライトについては フィルム状セメンタイトを起点に成悵していくことを示 している。.さらに球状化過程が促進される原因の一つと して変態によって各界面で凍絬された残留歪みを有する 非平衡な状態が $400^{\circ} \mathrm{C}$ 以上で解放されることによるも ので Photo. 6 B に示すように二相域に昇温直後では パーライトのラメラーの分断も顕著に認められこのこ とが球状化を促進していると考えられる. 涏来, 冷閪加 上を施した後に球状化処理を行うことにより促進される ことは郎く知られた事尖であるが，本実験材に打いて パーライト中のフェライトとセメンタイトの界酒にも転 位が多数垫められたことから (Photo. 4), 冷間加.T.に よってセメンタイトを変形破填させ，七メンタイトの分 断凝集を容易にする効果と同様の効果が奇与したものと 考えられる。また，フェライト・パーライト界面は再オー ステナイト化の際の優先サイトと考えられており, 界面 のフィルム状セメンタイトの球状化促進効果に対する役 割は大きい。最近, THOMPSON ら ${ }^{11)}$ によって車共析鋼の フェライト・パーライト界面の TEM 観察結果が報告さ れているように,多数の転位の存在するフェライト・パー ライト界面とか，パーライトの変態機構も従来共析鋼で 提案されている機構と異なることを認めている。このよ うに現在なお里共析鋼の変態機構についてまだ不明な点 が多い．球状化促進効果に扮ける界面の役割は上記のよ うに重要であり，变態の機構について詳細な観祭が今後 必要と考えられる.

\section{5. 結言}

制御庄延，制御冷却した中炭素鋼の超微細フェライト ・パーライト組織の下部組織の観祭結果と球状化処理の ための再加熱時に起こる組織変化から微紐組織における 球状化促進効果を検傠した結果, 次の結果が得られた。

(1)制御压延による動的再結昆状態のオーステナイト を $10^{\circ} \mathrm{C} / \mathrm{s}$ で急冷することにより，加工後のオーステナ イト粒度とほぼ同等の等軸で微細なフェライト・パーラ イト組織が得られ，フェライトの体積率が著しく増加す ることが恋められた。

( 2 ) TEM 観察の結果, 変態後の相界面は階段状であ り，かつ界面には粒界転位，フィルム状セメンタイトが 認められた。

(3) 再加熱により $400^{\circ} \mathrm{C}$ 以上で熱膨張摔に変化が認 められ，変態後の相界面に存在していた粒界転位はほと んど消滅することが認められた。 
以上の結果はフェライト・パーライト変態による組織 の形成に動的再結晶直後のオーステナイト粒界での残留 歪みが関係しており，かつ再加熱した場合に残留歪みが セメンタイトの分解を促進するものと考えられる.

\section{文献}

1) I. KozASU: Accelerated Cooling of Steels, ed. by P. D. Southwick, The Metallurgical Society of AIME, New York (1986), p. 15

2 ) $H$. Sawada, $J$. Koarai, $M$. Uemura and T. Ohshiro: Accelerated Cooling of Steels, ed. by P. D. Southwick, The Metallurgical Society of AIME, New York (1986), p. 589

3 ）金築 裕, 勝亦正昭, 澤田裕治: 鉄と鋼, 75 (1989), p. 1178

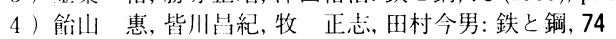

(1988), p. 1839

5 ) $R$. Kaspar, $W$. Kapellner and $O$. Pawelski: Z. Metallkd., 78 (1987), p. 569

6 ) $M$. Katsumata, $Y$. Kanetsuki, $M$. Sato, $F$. Li and $K$. Hosomi: Proc. Int. Conf. on Physical Metallurgy of Thermomechanical Processing of Steels and Other Metals, ed. by $I$. Tamura, Iron Steel Inst. Jpn., Tokyo (1988), p. 216

7 ) $R . A$. VARin and $K$. J. Kurzydlowski: Z. Metallkd., 74 (1983), p. 177

8 ) 牧 正志, 長道常昭, 阿部直樹, 田村今男: 鉄と鋼, 71 (1985), p. 1367

9 ) C. S. Smith: Trans. Am. Soc. Met., 45 (1953), p. 532

10) R. A. Varin: Mater. Sci. Eng., 66 (1984), p. 97

11) R. A. Varin: Phys. Stat. Sol. (a ), 73 (1982), p. K51

12) S. W. Thompson and P. R. Howel.l: Scr. Metall., 22 (1988), p. 1775 